\title{
Introduction: innovation and social cohesion in a learning economy
}

The radical change in the wider context in which national economies evolve, collaborate and compete has been alluded to along different dimensions and in different types of discourses. Some emphasize globalization and that nation states tend to loose some of their autonomy. Others point to the growing importance of knowledge for economic development and refer to the 'knowledge-based economy'. Yet others give information technology a key role in the process of change and some go as far as referring to a 'new economy' where old trade-offs between high rates of growth and stability have been relinquished.

The hypothesis put forward here and underlying the analysis all the way through is that we are moving into a 'learning economy' where the success of individuals, firms, regions and countries will, more than anything else, reflect their capability to learn. The speed-up of change reflects the rapid diffusion of information technology, the widening of the global market-place, with the inclusion of new strong competitors, deregulation and less stability in market demand. The acceleration in the rate of change implies that knowledge and skills are exposed to a depreciation that is more rapid than before. Therefore, the increase in the stock of knowledge might be less dramatic than it looks at first sight (OECD 2000b).

Different national economies exposed to the same transformation pressure have different capabilities to innovate and to cope with change and they have also established different principles and institutions for distributing the costs and benefits of change. The actual transformation they go through will reflect systemic differences in the way they innovate and build competence. They will be specialized differently, characterized by different institutional set-ups and the political culture will promote different types of state intervention to cope with the challenges raised by the transformation. We summarize such differences by referring to different national systems of innovation and competence-building. This signals that in the learning economy we need a wider perspective than the one associated with normal use of the term 'national system of innovation'.

To understand the process of transformation, it is useful to analyse and 
understand how specific national systems respond to global trends and challenges. Some national systems may, for historical reasons, be better prepared to cope with the new context than others. Some systems may be more innovative than others when it comes to developing policy strategies and institutional reforms that respond to the new challenges. The Danish system of innovation and competence-building is small in global terms but it has certain characteristics that makes it interesting as a 'model' for international institutional learning. Denmark has one of the most egalitarian societies in the world in terms of income distribution and at the same time it has an income level that is among the highest in the world. It has a high degree of gender equality, and well-developed local democracy.

The Danish system has some interesting features also when it comes to understanding transformation in the learning economy. As we will see, the system is obviously based on learning and on the use of competence in production and innovation. But it is not a high-technology economy and it is not an economy where formal science plays the most important role in processes of innovation. Our analysis of the Danish case thus illustrates that knowledge management and innovation policy involves a much broader set of institutions than those included in a traditional conceptualization of a national innovation system. In this sense, it may inspire broader strategies of policy-making and institutional reform. This may be especially important for other small countries and for developing countries where the focus on an isolated small science sector as the basis for knowledge-based development may actually be harmful to economic development.

Another specific reason for presenting the analysis of the Danish innovation and competence-building system to a wider audience has to do with the current stage of European integration where international benchmarking in different areas has become a major activity aiming at strengthening policy coordination at the European level. To strengthen the insight into the differences and similarities between European national systems of innovation and competence-building is important in order to avoid 'naive benchmarking' (Lundvall and Tomlinson 2001). Finally, the focus on Danish institutional characteristics may be helpful in overcoming some of the European contradictions between Anglo-Saxon pro-market strategies and Continental emphasis on state regulation and social security.

\section{FROM THE NEW ECONOMY TO A NEW ECONOMIC POLICY?}

The 'new economy' is a concept with many different meanings and connotations. In the financial journals it signalled, at least until the NASDAQ crisis in 
late 2000 and early 2001, that there is a new type of company connected to information technology and especially the Internet that grows very rapidly and constitutes attractive investment objects. In the realm of macro-economic debate the focus was on the new possibility of long-term, if not eternal, stable and strong economic growth (OECD 2000a; 2001b).

There has been certain envy in Europe of the new magic formula that apparently could guarantee permanent growth and low unemployment in the US. The downside - extreme and growing economic inequality - has been recognized and the general idea has been to integrate the positive aspects of the US model and combine it with 'social cohesion'. The European governments have thus given strong priority to increasing the role of venture capital and to stimulate the use of computers and the Internet. E-commerce and Elearning are among the areas given highest priority in Brussels.

The idea of using the US experience as a benchmark for economic policy and institutional reform has been undermined by the fact that in the US, the new economy, with the recession, has started to behave very much like the old economy. And the slowdown in economic growth has at its centre the very same financial institutional set-up - household investment in the stock market and a vibrant market-dominated financial system - that was regarded as a model for Europe just a year ago. The extreme focus on Internet and ICT sectors in the stock exchange created the financial bubble that is now bursting, and the heavy involvement of households contributes to the recession.

There is little doubt that technologies related to computers, telecommunications and the Internet have a great potential to increase productivity in the long run. But they will typically do so over a long period since they need to be supported by institutional and organizational change as well as by skill formation. The surprisingly strong and stable economic US growth can only to a minor degree be explained by the real effects of information technology and the Internet.

The most important factor has probably been the US economy and the US dollar remaining highly attractive for foreign capital, and the room for expansionary economic policy obtained hereby. The other two factors that may be of special importance are to do with access to labour reserves. At the bottom of the skill pyramid, the presence of a big hidden illegal labour reserve has had an anti-inflationary impact. At the top of the skill pyramid, the inflow of young ambitious scholars, not least from Asia, into the US university system has helped to avoid lack of academically trained labour.

The connection between the pattern of economic growth and information technology is certainly there. The extreme optimism created by 'new economy' hype has probably postponed the recession but also made it more painful to get out of. The Japanese financial bubble experience and the vain efforts to get out of stagnation illustrates how difficult it may be to overcome 
a bubble-based recession when both inflation and nominal rates of interest are low. What might come out of the US 'new economy' experience might at the end, actually, be 'a new economic policy' much more willing to accept high inflation in order to bring real rates of interest down. If this should happen Europe might take it as a 'benchmark' for reforming its EMU rules and its passive role in both monetary and financial policy.

\section{FROM THE KNOWLEDGE-BASED ECONOMY TO THE LEARNING ECONOMY}

Structural analysis of industrial developments shows that the sectors most intensive in their use of knowledge inputs such as R\&D and skilled labour are the ones that grow most rapidly. Also, the skill profile is upgraded in almost all sectors in the economy. The most rapidly growing sectors in terms of employment and value-added are, in most OECD countries, knowledge-intensive business services. These observations have led more and more analysts to characterize the new economy as 'knowledge-intensive' or 'knowledgebased', and there is little doubt that there has been a relative shift in the demand for labour toward more skilled workers. Even so, this term may be misleading because it does not fully capture the dynamics of what is going on.

The acceleration in the rate of change implies that knowledge and skills are exposed to a depreciation that is more rapid than before. The alternative hypothesis put forward here is that we are moving into a 'learning economy' where the success of individuals, firms, regions and countries will, more than anything else, reflect their capability to learn. So far the studies of national systems of innovation have given too little emphasis to the sub-system related to human resource development. This includes formal education and training, labour market dynamics and the organization of knowledge creation and learning within firms and in networks. This sub-system is now confronted with very strong needs for social invention in all national systems and quite a lot of the peculiarities of national systems are rooted in it. This is reflected in the use of the concept of national innovation system in this book. It has been widened to include all organizations and processes that contribute to competence-building.

The new context of accelerating change also calls for rethinking knowledge management at the level of the firm and innovation policy at the regional, national and European level. Industrial relations and the role of trade unions also need to be reassessed. While knowledge production and policy-making through decades have been characterized by growing specialization, the learning economy calls for lateral thinking and for an integration of separate perspectives and strategies. 
Transformation pressure

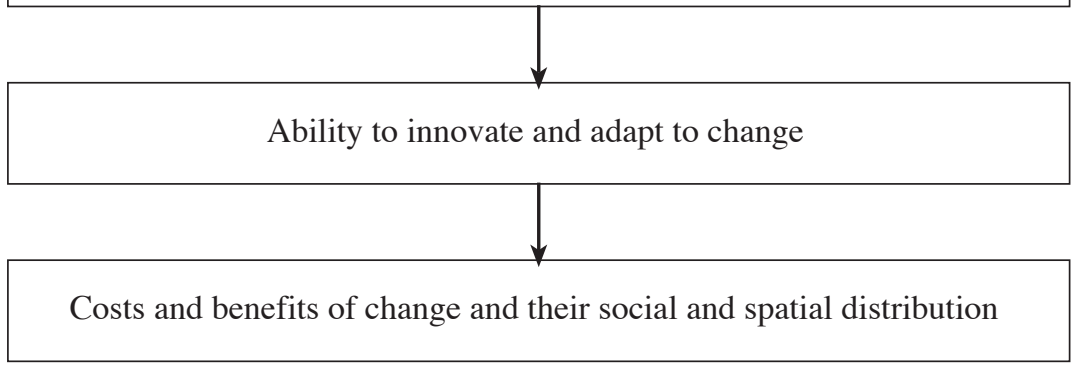

Source: Archibugi and Lundvall 2001, p. 6.

Figure 1 The basic model relating transformation pressure to the ability to innovate and to costs and benefits of change

\section{INNOVATION POLICY AS ONE ELEMENT OF A COORDINATED STRATEGY}

As indicated by the title of the book the focus is on innovation and social cohesion. This is reflected in our broad definition of 'innovation policy' and in the fact that we take into account how other policy areas influence or are influenced by innovation. Above, in Figure 1, some of the crucial aspects of the learning economy are illustrated with a simple model, where transformation pressure is linked to innovation and organizational change and to the costs and benefits of change. Through this model we can also see how different policy fields interrelate to each other and require coordination.

\section{Transformation Pressure}

One of the most fundamental factors affecting the transformation pressure is technical change. A second major factor is the competition regime. Governance regimes - the role of ownership and finance in managing the firms - affect the intensity but also the direction of the transformation pressure. Finally, the macroeconomic stance affects transformation pressure.

The development and widespread use of new technologies and especially of information and communication technologies has transformed fundamental aspects of the economy such as time and space. The wider set of competitors in world trade also reflects deregulation of trade and international financial flows as well as transport technologies that make it less and less expensive to 
move commodities and people over long distances. Privatization and deregulation increase the transformation pressure on parts of the economy that have so far been sheltered. These are the main factors that have increased the transformation pressure. To this should be added certain mechanisms that reinforce this tendency by introducing circular causality. Selection mechanisms in product and labour markets favour change-oriented organizations and individuals and thus increase the transformation pressure.

It is difficult to see what mechanisms within the economic sphere could halt this tendency. The full impact of information technology has yet to be felt; new entrants into world trade are on their way and further deregulation may be imposed in most countries by international organizations such as the IMF, the World Bank, the WTO, OECD and the EU.

The main limits to the process might be 'exogenous' and have to do with increasing costs in terms of potential social and environmental crises that might trigger popular resistance and political intervention. Popular resistance has become a real issue; after Seattle it has become increasingly obvious that globalization and international rule-setting are of broader concern in society in the developed as well as in the less developed countries.

\section{Ability to Innovate and Adapt to Change}

A key to successful innovation is to have a strong knowledge base including an R\&D capacity and a well-trained labour force. But as indicated by the concept of an 'innovation and competence-building system', many different agents, organizations, institutions and policies combine to determine the ability to innovate. Adaptation to change can take many forms and this is the subject of some of the most heated ongoing debates on economic policy. Flexible labour markets may be at the core of adaptation in some systems while others adapt more through functional flexibility within organizations. The creation of new firms may be a key to adaptability and innovation in some systems while others rely more on innovation and reorienting the activities of existing firms. In this book the focus will be on technical innovation, the introduction of learning organizations, the establishment of networking and on hiring and firing as different possible responses to the growing transformation pressure.

The new demands on the ability to innovate reflect a new mode of knowledge production. The new context puts a premium on interactivity within and between firms, and between firms and the knowledge infrastructure. These changes are reflected in new and more stringent demands regarding the qualifications of employees and management. Services, and especially knowledgeintensive services, tend to become much more important, both in their own right and for overall industrial dynamics. 


\section{Costs and Benefits of Change and their Social and Spatial Distribution}

The different forms of adaptability characterizing an innovation system will distribute costs and benefits of change differently. In the US system most of the costs are left to the individual. In Japan the firm has covered the costs of their employees. In most European countries the state takes on the cost collectively through insurance systems or needs-oriented systems. In Southern Europe the traditional family still plays an important role in caring for young and old people while the public welfare state has taken over most of this responsibility in Scandinavia. The UK system is the one closest to the US model and here neither the family nor the public sector takes a strong responsibility for those who lose in the game of change.

Data seem to indicate that, on balance, the distribution of benefits and costs has become more uneven during the last decade, at least within the OECD area. Profit shares have grown at the cost of wage shares in all parts of the OECD since the middle of the 1970s (OECD 1994a, p. 22). Earning differentials between skilled and unskilled workers have grown in the Anglo-Saxon countries and differences in employment opportunities between more- and less-skilled labour categories have increased in those, as well as in the other European countries (op. cit., pp. 22-3). The EU program for targeted socioeconomic research (TSER) demonstrates that the convergence of differences in income between rich and poor regions in Europe came to a halt in the 1980s (Fagerberg, Verspagen and Caniolis 1997).

Another set of costs arising from rapid change and which now needs to be tackled are those relating to global and local environmental problems: old and new industrialization and the intensification of transport locally and globally increasingly threaten the basic conditions for human life.

\section{ON THE NEED FOR POLICY COORDINATION AND ESPECIALLY FOR A NEW NEW DEAL}

This simple model demonstrates a need for coordination of a wide set of policies. Competition policy and macroeconomic policies need to take into account the capability to innovate and adapt in the national economy. The policies and institutions affecting the distribution of costs and benefits of change need to be designed in such a way that they do not undermine social capital and so that they contribute to the capability to innovate and adapt. Finally, all the policy areas relating directly to innovation and competence-building are crucial for economic growth and competitiveness.

A problem is that some of these policies are determined at the European level while others are respectively national or regional. There has been a 
tendency to move policies affecting the transformation pressure to the European level (common competition policy and the EMU) while leaving the other policies to the lower levels.

Another problem is that different national political cultures in Europe may give rise to different types of responses to the growing transformation pressure. Somewhat simplified, we can identify at least four different policy strategies (in real life these strategies tend to appear in different mixes in different nation states):

- Neo-liberalism: accept the increase in transformation pressure and leave it to the individual to cope with the costs of change.

- Neo-protectionism: reduce the pressure in order to reduce the costs for the individual.

- Old new deal: accept the increase in transformation pressure and compensate the losers ex post.

- 'New New Deal': invest ex ante in people and regions especially exposed to the transformation pressure - 'life-long learning with a social dimension'.

It is a serious problem for the European Union that the big member states tend to adhere to different strategies in these respects. The UK tends toward neoliberalism, France toward neoprotectionism and Germany toward the old new deal. In this book we use the Danish model as our basis for strongly recommending a common European movement in the direction of what we call the 'New New Deal'. Such a movement does not rule out a need to introduce mechanisms that reduce the transformation pressure, for instance through global agreements on regulation of financial markets. Neither would such a move make it unnecessary to use the old new deal instruments to help those who cannot be integrated into the learning economy.

\section{ON THE NEED FOR NEW RULES OF THE GAME AT THE GLOBAL LEVEL}

In the present era of the globalizing learning economy there are contradictions in the economic process that threaten learning and competence-building. Financial speculation seems to become more and more unhampered because it is now finance capital that judges what is 'best practice' among firms as well as among governments. This power of financial capital is one of the major factors that speed up the rate of change and thereby the need for accelerating learning. At the same time, the uninhibited rule of finance capital gets into serious conflict with some of the fundamental prerequisites for the sustainability of the learning economy. 
On the one hand, short-term economic calculations and speedy processes of decision-making (especially in financial flows) are becoming more and more important. On the other hand, competition depends more and more on dynamic efficiency rooted in knowledge or knowledge-related resources with long-term characteristics. These resources often take a long time and sustained efforts to build, but they may be quickly destroyed. The speed-up of change puts a pressure on social relationships in traditional communities. It contributes to the weakening of traditional family relationships, local communities and stable workplaces. This is important since the production of intellectual capital (learning) is strongly dependent on social capital. To find ways of re-establishing the social capital destroyed by the globalization process is a major challenge. Learning and innovation are interactive processes, which depend on trust and other elements of social cohesion.

It is a fundamental paradox that financial capital has been so successful in establishing itself in a dominant position in a 'learning economy'. Financial capital takes on a 'smart appearance' but basically it is 'silly'. This can be illustrated by different examples. In 1997 the Nobel Prize in economics was given to two US economists. Less than a year later those same two economists were responsible for hedge fund operations that brought the US and the global financial system to the brink of collapse. In Denmark the nationwide competition in investing in financial assets was won by a schoolboy without any earlier experience. The daily discourse in financial newspapers is characterized by a complete lack of consistency. It is quite legitimate for a commentator to propose one explanation for rising market values one day and exactly the same explanation for falling values the next day. No other area is so influenced by herding behaviour, and to define what it is that constitutes 'competence' is in this area obviously not simple. In economics the complete lack of 'wisdom' is compensated by the exaggerated technical complexity of mathematical models and econometric techniques.

These contradictions in the learning economy increase the need for policy coordination at the international level. A much stronger role for international agreements and rule-setting that rein in some of the wildest aspects of financial capital is needed. The Tobin tax is a modest proposal in this direction. As a first step to create a more long-term and stable context for learning processes it should be welcomed. Given the current US unwillingness to join any kind of multilateral agreements, a realistic first step toward global rules might be that Europe and other global regions establish some regulation of inflows and outflows of finance. This might at the same time help to build a more balanced and stable global economic system where there is not one single dominating economic power. 


\section{LEARNING BY COMPARING AND BENCHMARKING}

In this book we assume that political actors, policy-makers and scholars in other countries can learn something important from the study of the Danish system of innovation and competence-building. This kind of international institutional learning is radically different from the now so popular idea of 'international benchmarking'. Actually, showing the broad picture of a national innovation and competence-building system and thinking about it as a 'model' from which lessons can be learnt helps to understand the limits of 'naive benchmarking' and the impossibility of simply transplanting a single 'best practice' unchanged from one national system to another.

It is true that some of the underlying ideas behind benchmarking may be useful in relation to policy learning. To focus the attention on alternative ways used elsewhere of doing things and to reflect on what possibly could be learnt from these observations is useful and it gives rise to a process of 'learning by comparing'. But benchmarking might also be highly problematic and give rise to biased processes of institutional reform.

The very idea implicit in what we have named 'naive benchmarking' (Lundvall and Tomlinson 2001) - that there, in any narrowly defined domain, always exists one unique 'best practice' way of doing things and that this way, always, could and should be transferred from one context to another - is methodologically unsound. It is contradicted by almost everything we know from research on innovation and institutional learning. This research tells us, for instance, that the normal situation is one of coexistence of different good ways to do things, that this coexistence, and the diversity it gives rise to, is what makes systems adaptive and innovative, that what seems to be best practice in one period will quite obviously not be so in a later period and, finally, that the systemic context determines what is a good practice and what is a bad practice.

Benchmarking may also undermine democracy if taken too literally and too far. The very term 'benchmarking' indicates that what is at stake is a technocratic fine-tuning of procedures where political values and fundamentally different interests may be safely neglected. This might be less problematic in private sector benchmarking where there is a search for more effective ways to organize certain economic activities (but even here such procedures will often become elements in power games between different interest groups).

When it comes to agreement on how to design national labour market institutions or research and education institutions it is, of course, much more problematic to pretend that what is at stake is just a search for a 'pure efficiency' solution. One reason is that these institutions have become even more fundamental for income distribution issues and for issues related to citizenship. If we leave it to the expert to decide what is best practice and forget to consult the citizens, we will contribute to a kind of withdrawal from politics that 
seems to be one of the problems following in the wake of globalization processes.

\section{BENCHMARKING ACROSS SYSTEMIC CONTEXTS}

The idea of one unique 'best practice' way of doing things is not compatible with a system's approach. The system's approach assumes that normally the context - defined in its economic, technical, geographic, historical and cultural dimensions - has a great influence when it comes to determining what is best practice.

The concept 'innovation system' was introduced in the middle of the 1980s (Lundvall 1985, p. 55) to capture the relationships and interactions between R\&D laboratories and technological institutes on the one hand, and the production system on the other hand. The first widely diffused publication that used the concept of a 'national system of innovation' was the analysis of Japan by Christopher Freeman (1987). The concept was definitely established in the innovation literature as a result of the collaboration between Freeman (1988), Nelson (1988) and Lundvall (1988) in the collective work on Technology and Economic Theory (Dosi et al. 1988).

A system's approach to innovation makes it more complex to interpret the results of benchmarking and to define action on the basis of benchmarking. For example, it does not support strategies that have as their exclusive aim to increase the R\&D budget. Different types of competence matter more or less depending upon the prevailing industrial structure and institutional set-up of the national economy. Other factors have to be taken into account such as the demand side and user competence. Crucially, what matters most are relationships between the different elements of the system, and it is often extremely difficult to get good indicators for 'connectivity' and social capital. Having excellent universities does not help if the interaction with competent users of academic research is weak.

Most of these factors are localized and cannot easily be changed. To neglect the local, regional and national context when selecting and introducing new ways of doing things would be highly problematic, and to benchmark only those policies and institutions that share all of these conditions would, on the other hand, reduce the number of comparable units to a handful or even to zero.

\section{THE PORTUGUESE PRESIDENCY AND THE OPEN METHOD OF COORDINATION}

The Portuguese Presidency in the spring of 2000 introduced to the European Council an institutional innovation referred to as the 'Open Method of 
Coordination' and one way this idea has been made operational by national administrations, and especially by the different parts of the Commission, has been through the introduction of international benchmarking at the level of specific sector policies.

The implementation of benchmarking is expected to take place differently in different policy areas. At regular meetings representatives of national government will meet to consider progress made in specific areas of policy and it is assumed that this will also give inspiration for learning from each other's experiences. It is assumed that 'benchmarking' your own economy and using good practices from other countries as benchmarks is a way to stimulate progress toward shared objectives and instruments.

At the Lisbon Summit there were few reflections on the limitations of benchmarking. Since then some of the critical points made above have been considered, not least the reference to the importance of taking the systemic context into account. In an important document from the Portuguese Presidency distributed at the end of the Presidency period (Council of the European Union, 9088/00, 14 June 2000) the use of benchmarking and its relationship to the open method of coordination was further discussed and clarified. In this document it is pointed out that the open method of coordination aims to organize a learning process about how to cope with common challenges of the global economy in a coordinated way while also respecting national diversity. Further it is specified that benchmarking is only one element in the open method of coordination.

It is specified that the open method is 'open' because best practices should be assessed and adapted in their national context and because monitoring and evaluation should take the national context into account in a systemic approach. The open method is also open in the sense that the method should invite the participation of the various actors of civil society.

\section{INNOVATION POLICY, SYSTEMIC CONTEXTS AND THE US AS A ‘BEST-PRACTICE' NEW ECONOMY}

In the recent documents covering innovation policy (Communication from the Commission to the Council and the European Parliament, COM (2000) 567 final) there is also a tension between the recognition of the coexistence of specific national innovation systems (op. cit., 8) and the frequent references to the need to diffuse 'best practice' among member countries.

Some of the small national systems (Finland, the Netherlands, Denmark and Ireland) seem to be most successful in terms of innovation according to these preliminary attempts to establish an Innovation Scoreboard. It is interesting to note that this result coincides with the preliminary OECD analysis of 
economic growth in the new economy where some of the same small countries appear together with the US and Australia as the most successful ones in terms coping with the new context (OECD 2000a; 2001b).

Even so, there is a strong tendency in the Innovation Scoreboard report to emphasize the US as the leader and Europe as the laggard in terms of innovation. Ad hoc arguments are used to diminish the weight to be put on the good performance of small European countries. The report also seems to neglect the fact that in the central documents from the period of the Portuguese Presidency the objective is to combine competitiveness with social cohesion. The possibility that the small welfare economies illustrate a type of new economy, completely different from, and actually more sustainable than, the US type is not seriously considered.

At the same time this example demonstrates the limitations of using benchmarking in narrowly defined and separate policy areas. In order to understand what lies behind the relative success of the small countries it is necessary to understand how social and cultural dimensions are co-evolving with organizational and techno-economic developments.

At the Lisbon Summit in the summer of 2000, the Portuguese Presidency attempted to overcome the classical tension between the Anglo-Saxon emphasis on 'flexibility' in labour markets and the Continental emphasis on social security by combining the dynamic perspective of innovation with an emphasis on social cohesion. As will be seen, the Danish system represents a peculiar combination of successful incremental innovation, high rates of mobility in labour markets and a shared positive perception among most workers and citizens of social security paid by taxes. This is one reason why we believe that useful lessons may be learnt from the Danish case.

Another reason to pay attention to the Danish case when it comes to design institutions and policies is that the Danish system seems to cope quite well with the new context of the learning economy. The Danish economy is not strongly specialized in the production of high technology (with the exception of pharmaceuticals), but it is quite successful in using the new technologies including information and network technologies and the outcome in terms of employment and growth has been quite satisfactory especially over the decade of the 1990s.

\section{EMPLOYMENT, PARTICIPATION RATES AND PRODUCTIVITY GROWTH}

In Chapter 1 we discuss the relevance of the book in the specific Danish situation. We show that labour market participation rates are already high and that at best only limited increases can be obtained by further efforts to mobilize those outside the labour market. Therefore policies aiming at stimulating 
productivity growth become especially important. Understanding the workings of the national innovation system helps to coordinate these policies.

We also argue that it makes a difference if the mobilized workers join the labour market of their own free will or if they are forced into it by workfare programmes. A special weakness of the Danish system raised in Chapter 6 is the weak integration of workers with a different ethnical background. In this area there is need for innovative and more far-reaching solutions that open up entry into the regular labour market for workers who have been excluded from normal working life for a longer period.

In the context of European policy coordination increasing participation rates has been defined as a common objective. Denmark illustrates better than most countries some of the major benefits and costs that high participation rates bring along. There is little doubt that the high participation rates have been one element in the emancipation of Danish women. It has also in many other respects contributed to wealth creation and equality. The high degree of individualization and leaving it to public sector institutions to care for children and older people may be seen as a positive or a negative aspect depending on the value norms you start from.

Under all circumstances this is one area where 'benchmarking' needs to be combined with wide democratic debates on what kind of society people want. Just using the Nordic countries as benchmarks for countries such as Spain and Italy without popular debate is not acceptable.

\section{CHARACTERIZING THE DANISH INNOVATION SYSTEM}

In Chapters 2-4 the basic concepts of 'innovation', 'innovation system' and 'national innovation system' are introduced. Data on the relative performance of the Danish economy in terms of innovation are presented in Chapter 2. In Chapter 3 the fact that innovation is an interactive and systemic process is illustrated by Danish data on patterns of cooperation among firms, and among firms and knowledge institutions in connection with product innovation. In Chapter 4 it is demonstrated that the patterns of cooperation indicate that the Danish system remains national while becoming increasingly open to knowledge flows from abroad.

Chapter 5 characterizes the Danish innovation system in terms of specialization both when it comes to high-versus low-technology products and in terms of specific industries and technologies. It is shown that Denmark shares with other small highly developed countries a relatively weak specialization in high-technology products. Chapter 6 broadens the innovation system perspective by introducing specific characteristics of the labour market, the education system and the financial markets. It is demonstrated that these elements of the broader system of innovation and competence-building tend to support a Danish 
mode of innovation that is incremental and experience-based. Chapter 7 studies how the Danish system copes with the growing transformation pressure of the learning economy. It is shown that, at the level of the single firm, efforts to innovate and to introduce new forms of organization has to some degree overcome the job losses triggered by the increased transformation pressure.

\section{KNOWLEDGE MANAGEMENT AT THE LEVEL OF THE FIRM}

Chapters 8-13 put the focus on how firms adopt learning organizations, invest in human resources, enter into network relationships and hire and fire personnel. In Chapter 8 the focus is on the introduction of organizational traits characteristic of learning organizations. Chapter 9 analyses the knowledge production and knowledge flows between sectors and firms. Chapter 10 and Chapter 11 analyse network formation between firms and between firms and knowledge institutions respectively. Chapter 12 studies how firms make use of different types of continuous education and vocational training. Finally, Chapter 13 links organizational change at the level of the firm to the conduct of the firm in the labour market. Hereby, we establish a feedback effect from the micro-dynamics at the firm level to the dynamics in the labour market as a whole.

The analysis of the Danish case demonstrates, firstly, that the movement toward a learning economy is real. More firms tend to introduce learning organizations and give strong priority to the development of skills. It also shows that for most sectors the increasing transformation pressure tends to stimulate the movement in this direction. The performance of firms that have introduced traits characteristic of learning organizations is stronger in terms of productivity and employment growth.

Secondly, it is shown that there are quite important differences in how the increasing transformation pressure affects conduct among sectors. This is reflected in substantial differences between sectors regarding how far they have developed their models of knowledge management. While big manufacturing firms and business service firms are more advanced in terms of establishing learning organizations, the laggards are found in transport and especially in construction industries.

A third important result is that the predominance of small and medium-sized firms and the incremental mode of innovation in Denmark are reflected in the mode of knowledge management. Inter-firm networking is especially important in Denmark while the interaction with universities is less developed than abroad. Publicly organized and financed training and continuous education programmes are important in Denmark while firms' in-house investment in training courses is more limited. High rates of inter-firm mobility and less-developed geographical 
mobility promote learning in regions with a specialized industrial profile (industrial districts).

One of the most innovative features of the DISKO project is that it links on the one hand, firms' innovation activities and the wider diffusion of new organizational practices and, on the other hand, the overall labour market dynamics. This makes it possible to illustrate the model presented in Figure 1. The result is interesting. It shows that firms that introduce new organizational practises and engage in innovation, on average, create more jobs and also more stable jobs than firms that do not engage in change.

What is perhaps more surprising is that they create more jobs and more stable jobs also for unskilled workers. This gives a more optimistic scenario for the future of the learning economy than we expected when we started the project. Giving unskilled workers access to better learning capabilities and promoting the diffusion of learning organizations may thus be combined in the 'New New Deal' referred to above.

\section{WHAT CAN BE LEARNT FROM THE DANISH CASE}

In Chapter 14 we indicate what might be learnt from this study of the Danish innovation and competence-building system. There are several specific characteristics of the system that need to be taken into account before one considers the transfer of 'good Danish practices' to other national systems. The model might, however, serve as a prism through which the characteristics of other systems can be seen and as a contrast that brings out their characteristics more clearly. Finally, we hope that the Danish model can work as an inspiration for the development of new institutional combinations that may support the process of European integration on the combined basis of innovation and social cohesion.

\section{WARNING: 'UNSKILLED WORKERS' ARE NOT WORKERS WITHOUT SKILLS!}

In this report we make a terminological distinction between 'skilled workers' and 'unskilled workers'. This is a misnomer and a less than satisfactory translation of the original terms in Danish 'faglærte' and 'ufaglærte'. The first category refers to workers who have been through a specific 3-4 years of recognized professional training including theoretical as well as practical elements. The second category refers to workers who have not followed such a program.

The terminology is certainly misleading in Denmark where our case studies show that 'unskilled workers' often have substantial personal skills, as well as technical skills, and often involve in upgrading their competence. It also goes against our emphasis on competence building through experience. Below it will also be shown how 'unskilled jobs' are increasingly taken over by 'skilled workers' and this is reflected in a growing number of students and others with formal training joining the trade union for 'unskilled' workers (SID). 


\section{The objective: to stimulate a knowledge-based debate about innovation policy}

The purpose of this book is to stimulate comprehensive debate about how private firms and public organizations can organize themselves so that they are better able to utilize the technological and organizational possibilities available today. Our aim is to give a picture of the new challenges as well as of the strengths and weaknesses of the Danish economy seen in relation to such technological and organizational changes. On this basis we outline a number of courses of action, which we collect under the term 'innovation policy'.

Thus this is a research-based contribution to policy-making; based on the results we have achieved, it points out some of the critical decisions facing innovation policy today. It is important to establish that there are choices to be made between alternative courses of action which must be made on political grounds; these neither can nor should be based exclusively on scientific analysis. Many of the most crucial decisions must be made on the basis of democratic debate and must take into consideration the evaluations and priorities among the population. A project of this character can contribute by making people aware of new challenges, introducing new angles and pointing to certain characteristics of the Danish innovation system which people were not particularly aware of. It can also contribute to the establishing of a collective vision about the direction in which the social economy is developing, a vision that is both timely and realistic. In this way, the decisions that must be made anyway will, hopefully, become better informed and better coordinated.

\section{THE DISKO PROJECT'S RESULTS AS A POINT OF DEPARTURE}

During the period 1996-98 the DISKO project examined various aspects of the Danish innovation system. One of our points of departure was the fact that today we find ourselves in a learning economy, where the ability to acquire and use new knowledge is the key to economic growth and succes for individuals, firms and nations. Another feature is that the Danish economy, to an everincreasing degree, is becoming integrated in global economic processes. 
In terms of method, we have emphasized that the private firm is the breeding ground of technical innovation. This means that the development of the entire economy will be determined to a great degree by what happens in and around the individual firm. On the other hand, in the learning economy firms are dependent on the innovation and competence-building system as a whole. For instance, the development of qualifications and skills within a firm needs to be supported by outside knowledge in the form of an educated workforce and network relationships.

With this background, we organized four sub-projects (modules) to collect new knowledge in relation to the following three questions:

- How and to what extent do technical innovation, organizational change and not least human resource development take place internally in Danish firms? (module 1).

- How and why do firms interact with other firms and knowledge institutions to promote product improvement? (modules 2 and 3 )

- What does the Danish innovation system as a whole look like with reference to the production and dissemination of knowledge? (module 4)

We used various methods to collect new knowledge. Among other things we used primary statistics, questionnaires and interviews in connection with visits to firms. A crucial method that helped us to discover connections that have not previously been illuminated by traditional methods was the combination of qualitative data collected via questionnaires with register data from public statistics.

\section{A BROAD DEFINITION OF INNOVATION POLICY}

As will become obvious, we view innovation policy as a rather broad concept; we will also argue that it is increasingly necessary to introduce an innovation perspective into areas outside research and industrial policy. Education and labour market policies are essential to innovation and learning. Competition policy and general economic policy affect the economic climate in which firms operate; therefore these policies should to a certain degree be in harmony with innovation policy. Social policy and the institutions of the welfare state also influence people's attitudes toward often risky technical and organizational changes. Environmental and energy policy have great potential in terms of their interplay with technical innovation: the way in which these policies are framed can promote innovation, and conversely innovation can provide a solution to environmental problems. Behind this broad definition of the system and of relevant policies lies the idea that the current division of labour in research and division of labour among authorities has gone too far 
and that the learning economy calls for new attempts to reunify analysis as well as policy strategies.

\section{THE TOPICALITY OF THE PROJECT - MORE WORK OR MORE EFFECTIVE WORK?}

When this project was in the planning stages in the spring of 1995, the economic recovery had begun, but the problem of unemployment still dominated in Denmark. Currently (spring 2001) unemployment has been reduced to a level that is far below what was thought possible five years ago. The politicoeconomic debate to an ever-increasing degree now concerns bottleneck problems in the labour market, particularly the ways in which a greater portion of the workforce can be mobilized. This change makes the DISKO project's analytical perspective more relevant than ever. Changes in the innovation system that would allow for higher rates of growth in productivity would relieve the pressure on those politicians whose aim is to increase the Danish participation rate further, already high by international standards (see Figure 1.1). It is

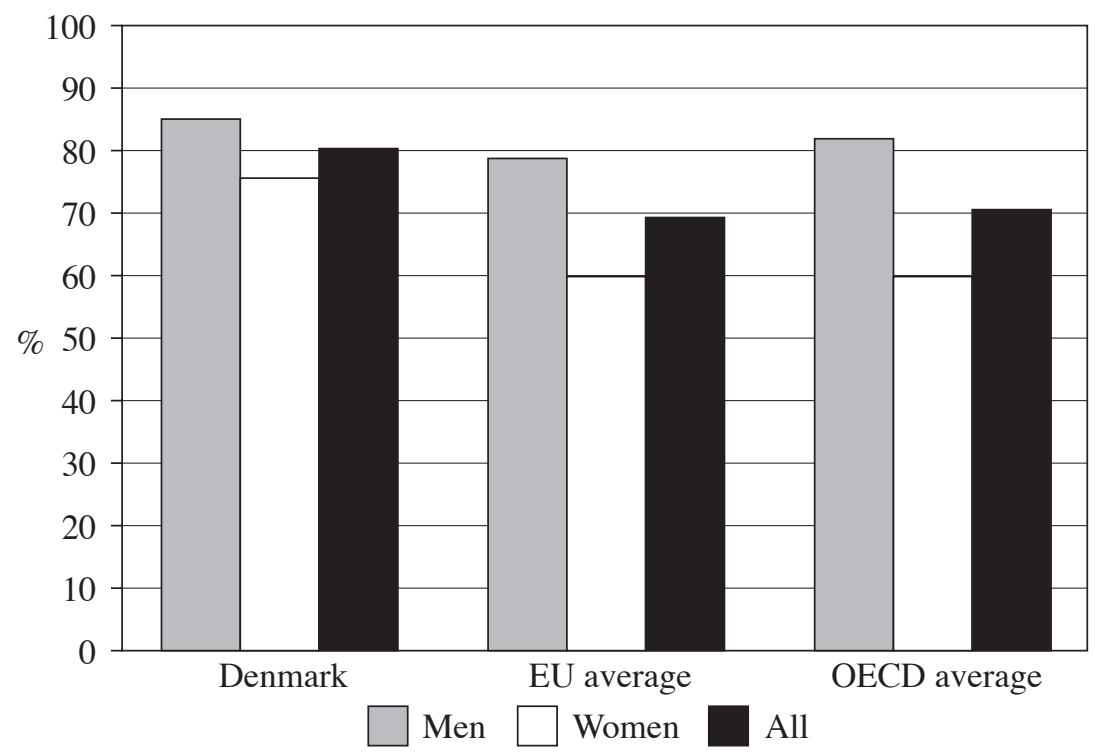

Source: OECD Employment Outlook (June 2000), pp. 203-5.

Figure 1.1 Participation rates for men, women and combined in Denmark compared with the average for the EU and the OECD in 1999 
surprising that the current debate in Denmark focuses so strongly on mobilizing the final reserves of the labour market as a prerequisite for future prosperity. Figure 1.1 illustrates clearly that the Danish participation rate is already high by international standards. It reflects in particular the fact that Danish women are much more active on the job market than their peers in other countries, something they have in common with Norwegian and Swedish women.

In contrast there is much to indicate that there is less value-added per work hour in Denmark than on average in EU and OECD member countries. In the manufacturing sector especially, productivity development within the last 15 years lies well below what we find in other countries (Regeringen 1999, pp. 82-3). Figure 1.2 compares GNP per capita and GNP per work hour in Denmark with the EU and OECD average. The fact that Denmark is above the EU average with regard to GNP per capita and far below it with regard to GNP per work hour is explained primarily by the fact that the Danish population annually delivers a greater number of working hours per capita. Figure 1.2 demonstrates that the high Danish national income per capita (exceeded only by Norway and Switzerland) reflects, in particular, the fact that the population to a large degree is active in the formal sector. Switzerland is the only country

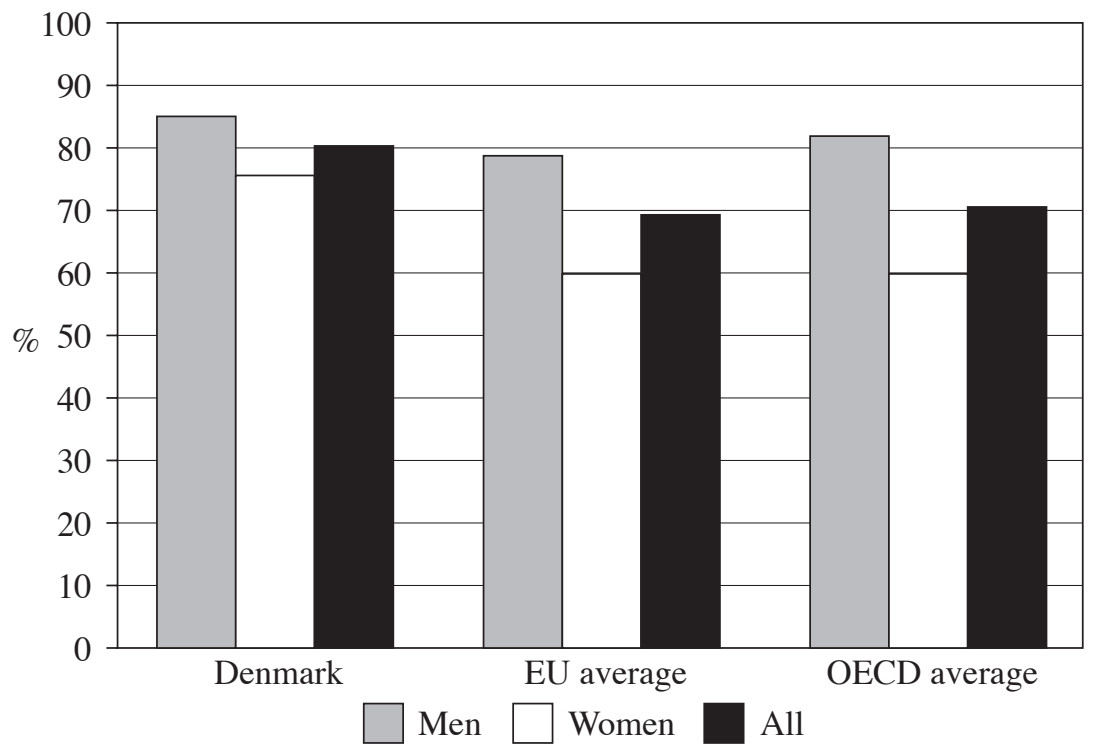

Source: OECD Science, Technology and Industry Outlook (1998), p. 100.

Figure 1.2 Comparison of value-added per capita and per work hour in Denmark and the EU in 1996 (total OECD = 100) 
that delivers more work per resident. Thus the Danish population delivered approximately 25 per cent more work hours per adult resident than the EU average for 1996. On the other hand, the value-added produced per work hour is rather modest in Denmark. In this area Denmark ranks near the bottom along with Sweden, Finland and Switzerland.

\section{BOX 1.1 LABOUR SUPPLY AND PRODUCTIVITY}

When such great emphasis is placed on expanding the collective labour supply, it is interesting to note that there may be a negative correlation between the larger supply of labour and easy access to labour on the one hand and, on the other hand, strong growth in productivity. In the 1950s and 1960s a clear negative correlation could thus be observed between the aggregate rate of unemployment and productivity growth in the Danish and the Swedish economies (Lundvall 1974); this connection was also present during the inter-war years in the Danish economy (Pedersen 1977). These correlations reflect, among other things, firms' flexible adaptations of organization and technology during periods of scarcity. When firms experience a shortage of manpower, they will seek ways of economizing in its use; this leads to more rapid growth in productivity. In the short term the mobilizing of the least-productive parts of the labour force will, of course, also affect labour productivity in a negative way.

For social reasons it is doubtless a good idea to provide people now living on public benefits who wish to return to the labour force with a chance to regain their foothold. This could be implemented, for example, through jobs with flexible requirements and/or in protective environments or through the relaxation of rules prohibiting part-time work solutions and partial retirement. At the same time, one must not forget that the high Danish participation rate, combined with the high mobility of the workforce, puts greater pressure on the entire population with regard to the structure of everyday life. Some of the elbow-room that has been created, for example through government schemes guaranteeing the rights to paid maternity leave, leave for education and opportunities for early retirement, should be evaluated in this light. A number of essential social functions performed by housewives in other European countries must in Denmark be carried out during the leisure time of men and women who work full time. These aspects of the Danish employment system 
also need to be considered by policy-makers in other countries in Europe. The common goal of the European Community to increase participation rates in all European countries has recently been confirmed by the meeting organized by the Swedish Presidency at the Stockholm Council meeting. If realized, many of the characteristic features and trade-offs of the Scandinavian societies will appear in a similar form in other parts of Europe.

A reduction in the proportion of the population that relies on public benefits and an increase in the proportion of the population with jobs would certainly contribute to economic growth. One must keep in mind though that such a gain is a one-time gain and that there is a limit to how far one can move in this direction without negative effects on total welfare, for instance through making it necessary to introduce draconian workfare programmes that neglect the needs and wishes of those to be mobilized. This does not hold true for a strategy that focuses on promoting productivity growth. A one per cent increase in annual growth in productivity would provide a permanently increasing standard of living. Nor can we rule out the possibility that the years of low productivity growth in the Danish manufacturing sector have left a backlog that relatively modest efforts could eliminate.

One should be cautious when interpreting international productivity comparisons. There are several problems in measuring productivity and comparing it internationally: a decline in productivity growth may reflect, for example, a shift in demand toward sectors with low productivity. This last argument is, however, less valid when it comes to comparing productivity levels in a sector such as manufacturing, which is exposed to competition and export-oriented. In any case there is cause to examine more carefully the background for the low productivity growth in this sector in Denmark. One hypothesis that should be examined is that weak competition in some service sectors, combined with a monopolistic pricing strategy, gives a distorted picture of productivity development in the manufacturing and service sectors respectively.

It might seem as if the current politico-economic debate is based on a traditional theory of growth, in which growth is seen as something that arises primarily from a greater use of the production factors of labour and capital. The current theory of growth, which is increasingly used as the basis for the analyses carried out by the OECD and the EU, emphasizes that growth is determined to an increasing degree by technological and organizational change as well as by the ability to acquire and use knowledge. In this connection, it is interesting that the OECD refers to recent analyses showing that up to 90 per cent of the combined productivity growth in the private sector can be traced to changes at firm level (OECD 1998a, p. 111). Here, we will focus on the technological and organizational changes in Danish firms, that is, on processes that have a vital impact on the growth of firms' productivity. 


\section{BOX 1.2 THE NEED TO CONNECT THE ANALYSIS OF WHAT IS GOING ON INSIDE FIRMS TO THE PRODUCTIVITY OF THE ENTIRE ECONOMY}

In the 1998 Business Review the promotion of productivity is emphasized as a future strategy; an 'unfortunate' specialization in production and trade is unequivocally named as the most significant reason for Denmark's low hourly productivity (Erhvervsredegørelsen 98). No analyses of productivity development are given in this light, however, neither in the Business Review nor in the most recent analyses of the productivity problem carried out by the Ministry of Labour (Regeringen 1999, pp. $63 \mathrm{ff}$.).

Given the importance of productivity growth for the future development of prosperity, it is remarkable how little systematic knowledge there is about the reliability of international productivity data and the underlying causal relations. At the same time Denmark and the other Nordic countries have data sources that have not been fully exploited, including the IDA database, which could be used as the basis for detailed firm-based analyses. This demonstrates the need for a coordinated analytical effort of specialization patterns and productivity in a Danish context. Such an effort should aim at explaining growth in the Danish economy as a whole, but it might begin by examining what occurs internally in the individual firm, the population dynamics of firms and then to link these changes and changes in the sector structure to the observed pattern of aggregate growth (Carlsson 1980).

\section{IS INNOVATION A PANACEA?}

It might be particularly tempting for researchers in innovation to become infatuated with the object of their research. 'Innovation' has a seductive sound; it points the way toward enterprise, progress and change. For this reason, a few thoughts on the value of innovation are appropriate here.

If technological and organizational developments in the Danish economy stopped completely for several years, the economy would not just stand still: productivity and the standard of living would actually decline. Danish firms would lose market share, unemployment would increase, and public service at 


\section{BOX 1.3 STRIKING A BALANCE BETWEEN WORK AND LEARNING}

The current focus on the supply side of the labour market also indicates a risk that industrial policy will come to depend too heavily on market conditions. There is a risk that the importance of lifelong learning will be de-emphasized during periods when manpower is scarce. It is vital for long-term growth potential that both public policy and firms' personnel policy is formed in such a way that workers are continuously given the opportunity to attain new knowledge, also in periods of prosperity and labour shortages.

the level we are familiar with would be unaffordable. It is doubtful whether such a standstill is at all compatible with capitalist production methods. It is also difficult to see any realistic solution to the challenge presented by the environmental challenge that does not require a high degree of technical, institutional and organizational change.

Thus innovation is a prerequisite for reasonably stable and sustainable economic development. This does not mean, of course, that all technological and organizational changes contribute positively to the welfare of society. New weapon systems may increase the risk of violence; the Internet may be used by the Mafia; new chemical products may turn out to have unintended effects on the human organism; genetic manipulation intended to fight hereditary diseases raises nearly unsolvable ethical dilemmas. New technology may be abused as well as used, and technological progress will introduce new risk factors into our daily lives.

We should add to this the fact that the actual process of transformation may have direct negative results on economic growth. The innovation process can be channelled into particular areas (nuclear power technologies rather than the search for renewable energy sources) which are not the most promising, economically speaking. And an exaggerated fixation of actors on technology as a patent solution, one that ignores the need to develop human resources and organizational change, may result in declining productivity. Finally, the tempo in the innovation process may be increased so drastically that it prohibits radical change at a deeper level and threatens economic stability - 'intellectual strip-mining' indicates a process where moving rapidly ahead on well-established trajectories may imply that too few resources are used to explore alternative ones. 


\section{THE DIRECT AND INDIRECT COSTS OF INNOVATION}

Joseph A. Schumpeter emphasized the importance of innovation for economic development more than anybody else did. At the same time he described innovation as a process characterized by 'creative destruction'. The destructive element reflects the fact that every innovation process involves both direct and indirect costs. The direct costs have to do with the development, implementation and use of something new, and these costs are borne primarily by those who are directly involved in the innovation process. The indirect costs, on the other hand, have an effect on people and organizations that have very little influence on the innovation process, for example:

- Employees of non-innovative firms who watch the value of their qualifications declining on the labour market.

- Owners of firms who see the value of their investment declining because their firms are losing market share to innovative firms.

- Taxpayers who see a public infrastructure that has been built using public funds becoming obsolete because of the relocation of production.

- Consumers who experience the loss of value of durable consumer goods they have invested in (computers, for example) when new versions come onto the market.

The transitions that innovation gives rise to in terms of frequent job changes, relocation, new job demands and so forth may be experienced more or less negatively by the people who are affected. Some people (particularly the young and highly educated) will view many of these changes positively, as offering upward social mobility, variety and interesting challenges, while others (especially older people with few, narrow or obsolete qualifications and little say in the decisions that affect them) will primarily experience them in terms of increased stress and new demands that cannot be met.

One fundamental problem related to the rate of innovation is the polarization that has taken place on the labour market in every single OECD country since the early 1980s. It reflects, among other things, that in 'the learning economy' bright people who are quick learners are rewarded, while residual groups tend to be pushed out of production and society (OECD 1994a).

With this in mind, it is obvious that it is neither fruitful nor meaningful to take a general stand, either positive or negative, on technological and organizational transformation. Strategies are needed that consider and take into account both the advantages and the costs involved in the innovation process. How a society organizes the distribution of the indirect costs and benefits of the transformation process is crucial. Who shall bear the brunt of these costs: the entire community, that is, the state and its taxpayers, as in Denmark; the 
business community, as in Japan; or the individual, as in the United States? The choice made in this respect will affect both innovation and social cohesion. It is of course also a key and highly controversial issue for the European policy coordination now under way.

\section{BOX 1.4 THE DANISH EMPHASIS ON CONSENSUS-BUILDING AND TECHNOLOGY ASSESSMENT}

Denmark has developed institutions that systematically and constructively assess technological developments and their impact on everyday life. The Danish Council of Technology and the consensus conferences it organizes have a more central position in Denmark as a forum for instigating debate than corresponding institutions in other countries. Consensus conferences bring together panels of ordinary citizens with experts and the outcome is well reported in the press and used as input for parliament when it designs new regulations and laws.

\section{COMPETITIVENESS, SOCIAL CAPITAL AND LEARNING IN SMALL COUNTRIES}

In the National Council for Competence's report (Mandag Morgen 1998, p. 28), an especially interesting diagram was constructed by combining qualitative data from interviews about social relations with the IMD's evaluation of the competitiveness of several countries. The diagram, given here as Figure 1.3, illustrates that most small countries in Europe combine social cohesion with being highly competitive. They are characterized by high scores on both these accounts.

Part of the background for the cohesiveness is that in these small countries, social and political systems have been developed in such a way that the costs of the innovation process are shared on the basis of solidarity principles. Sweden's low placement in terms of competitiveness is interesting. This possibly reflects a somewhat incoherent combination of a rigid system of labour market agreements, concentration on large-scale operations, and the extensive globalization of the largest Swedish firms. It has been claimed that this, combined with factors related to industrial structure, has led to a lack of internal adaptation and the exodus of capital on a large scale (Mandag Morgen 1998, p. 14). Cohesiveness, which can also be said to be one important 
High competitiveness

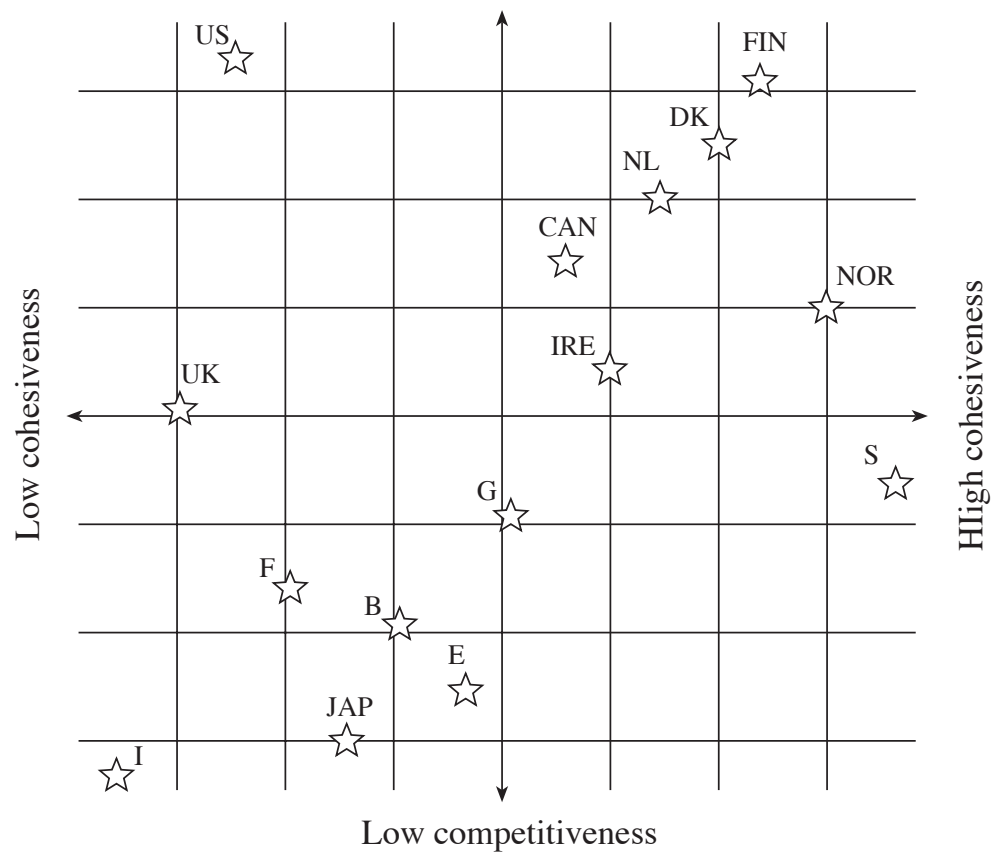

Source: Mandag Morgen (1998), p. 28.

Figure 1.3 Competitiveness and social cohesiveness in OECD countries

element of 'social capital', has such great importance in the learning economy because effective learning (unlike the processing of information) presupposes trust and cooperation. While small countries may remain handicapped in some product areas dominated by formal knowledge, they can penetrate in other knowledge-intense areas anchored in interactive learning processes (see Chapter 5).

As we shall see, it is a crucial challenge for a small country such as Denmark to find new ways to tackle the marginalization of those who have difficulty keeping up with the accelerated rate of change in the learning economy. In the next chapter, we will argue that Denmark will never become the breeding ground for epoch-making, radical technical innovations, but that does not rule out the fact that it may remain a pioneer with regard to radical 'social innovations'. And, in a global perspective, there is perhaps a greater need for the latter than for the former. 


\section{BOX 1.5 SOCIAL CAPITAL AND INDUSTRIAL POLICY}

Social capital, is a relatively new concept first introduced by sociologists and political scientists; it has, however, gradually gained a footing in analyses of economic development (Coleman 1988 and 1990; Putnam 1993; Fukuyama 1995; Woolcock 1998; OECD 2001a; Government Institute 2000). Basically, the concept refers to the degree to which, in civil society, there is a tradition for cooperating with others outside the narrow circle of the family and for solving problems together. If a society has well-developed social capital, transactions and learning processes can be enacted without too many legal or practical problems. To ensure competitiveness in the long run, social capital must be maintained. Russia is an example of what happens to economic development when social capital is undermined.

Historically this type of local resource has constituted a comparative advantage, particularly for small countries (Kuznets 1960; Svennilson 1960). A very important function of modern nation states has been to accumulate and reproduce social capital. This could help to explain the fact that small countries, in spite of not always being able to exploit the advantages of scale in the production of goods and knowledge, have been able to achieve high growth rates and living standards.

Conversely, swindling and fraud in business and in society at large serve to undermine social capital and weaken economic effectiveness. Effective action against economic crime can thus be seen as a measure that promotes innovation. Nor should we underestimate the importance of political processes that are based on principles of honesty, accountability and freedom from corruption.

Growing inequality in terms of economy and power risks weakening growth, particularly in small countries, the competitiveness of which is to a great degree based on cohesiveness. For the project of European policy coordination it is a major challenge to develop institutions that support the reproduction of social capital. The popular resistance to the European project in member countries reflect a strong doubt regarding the capability 
of Europe when it comes to taking over this function from the nation state. If the European project ends up by neglecting the 'social dimension' and exclusively becomes an Anglo-Saxoninspired free market zone this resistance will become even stronger.

\section{SUMMARY}

The major purpose of this book is to stimulate debate about the challenges and opportunities facing the Danish innovation system. In this connection we will point out various courses of action for individuals, organizations and public authorities. Our point of departure is a comprehensive empirical analysis of the characteristics of the Danish innovation system and an analysis of data from official publications.

In the first half of the book we will introduce the fundamental concepts and perspectives that will be used. Thereafter the innovation system as a whole is analysed. In the second half of the book, the focus is on competence-building within firms. We conclude with a discussion of what can be learnt from the Danish case. 